\title{
The ethical dilemma of placebo use in clinical practice
}

Review

Chun-Yi Xu*, Chun-Ming Yuan

Department of Orthopedics, Sichuan Academy of Medical Sciences \& Sichuan Provincial People’s Hospital, Chengdu, Sichuan 610000, China

Received: 18 November 2019; Accepted: 20 December 2019; Published: 20 September 2020

Abstract: The clinical use of placebo that involves some ethical issues has led to much controversy. From the standpoint of both supporters and opponents, this article discusses this topic from three ethical principles such as beneficence, justice, and autonomy and also gives the recommendations. Finally, the moral dilemma caused by the different views between nurses and doctors in clinical practice is discussed.

Keywords: placebo • ethical dilemma $\bullet$ moral distress

(c) Shanxi Medical Periodical Press.

\section{Introduction}

As a clinical nurse working in the surgical department, the author often delved into the use of painkillers, especially for postoperative patients. However, the placebo intervention (e.g., a saline injection) is sometimes used following the doctor's instructions without telling the truth to patients, which is to prevent the patients from becoming addicted to painkillers. In this process, the author's thinking is triggered based on the question of whether this is ethical: "How would I feel if I am a patient, and if the doctor prescribed a placebo without telling me the truth?" This article will raise this question to explore the ethical issues of placebo use in clinical practice.

\section{Definition}

A placebo is an inert substance that lacks any medicinal properties (e.g., a sugar pill and a saline injection), which is a substance that is deemed to be inactive (p. 2710). ${ }^{1}$ The placebo is often used to calm patients, avoid unnecessary medication, and is widely accepted by healthcare professionals. $^{2}$

\section{Ethical considerations}

\subsection{Principle of beneficence}

Those who support the use of placebo believe that the placebo effect is real, which refers to the improvement of clinical symptoms as a response to placebo intervention (p. 566). ${ }^{3}$ They argue that if the placebo is effective and can make the patient feel comfortable, then it is acceptable. More importantly, compared with real drugs, placebos are more cost-effective and have no side effects. ${ }^{4}$ Placebo supporters believe that the controversy over placebo has led to excessive attention

How to cite this article: Xu CY, Yuan CM. The ethical dilemma of placebo use in clinical practice. Front Nurs. 2020;3:203-208. 
to deception, while the beneficial effects of placebo are often underestimated or ignored. ${ }^{5}$ The Helsinki Declaration as the "gold standard" is an indication of how to conduct controlled research on humans following ethical principles. Although effective treatments are available, the Helsinki Declaration still allows the use of placebos, which is justified when its use does not cause irreversible harm or considerable suffering to the patient. ${ }^{6}$ In recent years, even when the use of placebo has become highly controversial, the Helsinki Declaration does not prohibit its use, which is enough to prove its value and its beneficial effects. These supporters claim that the principle of beneficence is superior to the patient's autonomy. When deception is to serve the patient's welfare, then it is justified. From this point of view, paternalism is reasonable. ${ }^{2}$

A lot of researches have revealed that placebo is effective. ${ }^{7-9}$ The most common explanatory mechanism of the placebo effect is conditioned reflexes. Various factors in the clinic (e.g., shape of pills, white coats, and the peculiar smell of hospital) can act as conditional stimuli to elicit a therapeutic response that stimulates brain biochemical changes in patients, which is very similar to drug induction because these factors have been paired with the response in the past. ${ }^{10}$

Beneficence refers to actions that promote the wellbeing of others, which involves balancing the benefits with the risks and costs of treatment (p. 1555). ${ }^{11}$ Since placebos have no adverse effects and also being costeffective, placebo supporters consider that it is in line with the principle of beneficence. ${ }^{12}$ On the contrary, the opponents claim that there is the risk of undertreatment with placebo. Chua and Pitts ${ }^{11}$ pointed out that when using a placebo for depressed patients, it may increase the suicidal tendencies of patients. From this point of view, the use of placebo violates the principle of beneficence.

\subsection{Principle of justice}

Another standpoint from the proponents of placebo is that since it is an effective and economical intervention, there is no need to use more expensive real medications, and the clinical use of placebo is in line with the principle of justice, ${ }^{12}$ which means that healthcare professionals are obliged to promote justice in the distribution of the inadequate medical resources (p. 197). ${ }^{13}$ However, placebo opponents have a completely different view. They claim that the patients who receive placebos suffer from injustice because unlike standard medications, the effect of placebo is unpredictable and unreliable. ${ }^{2}$ Placebos are more to relieve the patient's psychological burden than to treat the actual effect of disease, and the major factor of positive effects of placebos is in the psychosocial context, not the placebo itself. Doctors' positive clues play a significant role under such circumstances. Thus, placebo intervention is regarded as a form of interpersonal healing. ${ }^{11,14}$ In this case, a placebo is unnecessary if a doctor's good bedside manners can achieve a healing effect. ${ }^{15}$

\subsection{Principle of autonomy}

In addition to the considerations of beneficence and justice, the ethical challenge caused by using a placebo is more due to the threat to reduce the patients' autonomy. Autonomy is often referred to as self-determination, which means that a person makes choices based on his or her values and wishes (p. 2). ${ }^{16}$ Respect for patient autonomy has become increasingly prominent in nursing and medical practice in recent years. More and more people realize that patients have the right to self-determination of the treatment and care they receive. ${ }^{13}$ However, the clinical use of placebo always involves deception. Patients are rarely informed of the use of placebos, as this information may reduce the effectiveness of placebo treatments, which is therefore ethically problematic. ${ }^{2}$ In Western medical ethics, it is generally believed that doctors should inform patients about the proposed treatment, possible adverse effects, and alternatives. Patients should only be treated when they agree with it. From this perspective, a deceptionbased treatment decision is unfathomable. Even if it is done with good intentions, the unilateral decision of what treatment is beneficial to the patient is improper for today's view of the non-hierarchical doctor-patient relationship. ${ }^{17}$ As a result, prescribing a placebo without telling the patient is a violation of trust. ${ }^{18}$

One problem that placebo supporters rarely discuss is that when patients know that they are treated with placebos, it is difficult to predict their responses. Although some may be grateful if the placebo works, others may feel angry or betrayed after they become deceived. ${ }^{2}$ If the patient feels distrustful, the relationship between healthcare professionals and the patient will be undermined. Even worse, it causes psychological stress to the patient, which may lead to worsening symptoms or new symptoms. ${ }^{17}$ Fässler et al. ${ }^{19}$ stressed the significance of trust in the relationship between patients and healthcare professionals. Patients who suffer from diseases are dependent on someone else, while healthcare professionals as healers to offer help are not in a reciprocal position; so, patients find a need to fall back upon someone to feel supported, which makes the doctorpatient relationship particularly crucial and trustworthy. Therefore, the patient's autonomy should be respected to foster a relationship of trust. ${ }^{20}$

Placebo supporters believe that the patient's autonomy has been compromised by illness or addiction. In this case, deception is justified for the benefit of the patient. 
An insistence on telling patients the truth will violate their autonomy because it deprives them of the most beneficial option. ${ }^{12}$ However, placebo opponents argue that deception is incompatible with dignity, just as we do not like to be deceived, even if the lies are well-intentioned. Confucius $^{21}$ said, "What you do not wish for yourself, do not do it to others." Therefore, the clinical use of placebos should be banned. In terms of patients with drug addiction, they should be told the truth to make them aware of the issue, which helps them avoid further addiction. ${ }^{2}$ Incompetence should not be the condition of making deception acceptable. A patient as a person should be treated with respect and their dignity should be acknowledged. ${ }^{13}$

\section{Recommendations}

A systematic review ${ }^{19}$ involving 22 studies from 12 different countries shows that $17-80 \%$ of physicians have prescribed placebos while $51 \%-100 \%$ of nurses have used placebos in their clinical practice. The motivations and attitudes toward clinical use of placebo are complicated and health care professionals are always faced with a dilemma. The main issue is establishing how healthcare providers can take optimal advantage of the placebo effects consistent with their duty to acquire a patient's trust and obtain informed consent. ${ }^{22}$

Undoubtedly, respect for patients' autonomy and their choices are recognized as the core principle of medical practice. However, when the patients' choices conflict with professional advice or the best existing clinical evidence, respecting the patients' autonomy may compromise the professional accountability and the patient's welfare. Should we respect any decision

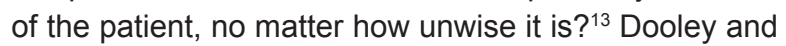
McCarthy ${ }^{23}$ proposed a "middle ground" approach that when the patient's choice is not the optimal decision, persuasion can be used as a legalized interference; unlike coercion and manipulation, persuasion is a dialogical approach based on shared communication and professional engagement, which makes autonomy and beneficence become mutual supports. It is shown that while patients value autonomy in the decision-making process, they prefer to adopt a more shared approach to decisions within a trusting relationship with healthcare professionals. ${ }^{24}$ To balance the diverse ethical principles, the American Medical Association's Code of Ethics ${ }^{25}$ suggests that the clinical use of placebo should obtain the patient's general consent, which means that the patient should agree to use a placebo but cannot identify it. A placebo can still be effective if the patient does not know the precise timing of its use. In this way, the patient's autonomy is respected while they can still benefit from the placebo.

\section{Moral distress}

Nursing is a relational discipline, traditionally considered a moral practice involving care and compassion. As the role of patient advocates, nurses have the moral and professional responsibility to question, reflect, and defend the patient. ${ }^{26}$ However, nurses continue to face ethical challenges in practice because the intimate nature of nursing involves caring for the patient's body and integrity, this can be in conflict with current policies and practices, which can be detrimental to the nurse, leading to moral distress. ${ }^{27}$ In nursing, moral distress refers to the psychological disequilibrium caused by the painful feeling that nurses cannot take ethically appropriate actions based on their conscience or knowledge (p. 679). ${ }^{26}$ In the clinical use of placebo, sometimes nurses have inconsistent views with doctors, but they have to comply with the doctor's orders although they disagree. In such a case, the nurse may experience moral distress, which arises when individuals' actions do not accord with their moral convictions. ${ }^{13}$

The main obstacles that prevent nurses from taking the morally appropriate action are lack of time, restraining medical power structures, and institutional rules and regulations. ${ }^{28}$ The shortage of nurses requires them to take more tasks that increase their workload and thereby reduces the quality of care, which results in decreases in opportunities for nurses to develop an interpersonal relationship with patients. As patient advocates, nurses place a high value on the nurse-patient relationship, and when nurses cannot achieve their core values, especially the value of holistic care, they will feel frustrated and experience moral distress. ${ }^{29,30}$

Another factor that causes moral distress among nurses is the hierarchical relationship between nurses and doctors. Compared with doctors who play the role of "head of the family," nurses are in less powerful positions in the healthcare hierarchy, which is considered to be the root cause of the problem. ${ }^{31,32}$ Medical hegemony continues to prevent nurses from substantially affecting the decision-making process. Medical decisions are invariably given higher priority than nursing decisions. When nurses believe they have little influence on treatment decisions with which they disagree, they will feel powerless and believe their expertise is unrecognized and devalued. These conflicts usually become most apparent when nurses and doctors have opposite views of what is the best care and treatment for patients. ${ }^{30}$

Institutional rules and regulations are also barriers that make nurses impossible to execute the right ethical action. According to Jafari et al., ${ }^{33}$ the institutional rules and regulations require nurses to follow the doctors' orders even for trivial things that give nurses a feeling of incompetence. Nurses often find it difficult to 
enforce their professional and ethical values because of the constraints within their practice environment, and the nurses' lack of autonomy in making independent decisions plays a vital role in their moral distress. ${ }^{34}$

When these constraints impair the nurses' ability to take action, nurses experience moral distress, which is a major problem in the nursing profession that affects nurses across all healthcare systems. Unresolved moral distress can lead to nurses' job dissatisfaction. ${ }^{35}$ According to Ulrich, ${ }^{36}$ in clinical situations, nurses who experience moral distress are more likely than others to deny responsibility for their actions and to blame nursing and hospital management for perceived problems in the work environment, so they will become increasingly dissatisfied with their work.

Besides, moral distress is considered harmful to the moral integrity of nurses, thus affecting the quality of care. ${ }^{37}$ Moral integrity refers to performance based on one's moral code and being the kind of a person nurses want to be. These people are characterized by honesty and trustworthiness, who show courage, patience, and perseverance in the face of conflict. They always do the right thing even when they encounter difficulties or others disagree. ${ }^{37,38}$ However, when nurses are constrained by external forces and cannot do what they believe is morally correct, they will experience moral distress and feel that their moral integrity is compromised, and their core values are violated. Consequently, nurses may be inclined to abandon personal beliefs of right and wrong to fit into the medical environment. They gradually succumb to environmental pressures to meet the expectations of others, which is a strong negative experience that can lead to burnout and leaving the profession. ${ }^{39}$

The time pressure in nursing care leads to the neglect of ethical issues, and nurses are usually reticent in this regard. De Veer et al. ${ }^{28}$ claimed that the reason behind this reticence is the lack of professional self-respect, causing a hollowing out of the nursing profession and it, in turn, brings about more lack of appreciation. This is a vicious circle. Catlin et al. ${ }^{40}$ pointed out that dealing with moral issues is not only a personal issue but also a social one. Empowering nurses to practice according to the professional standards will be an approach to break this vicious circle.

Following Wocial and Weaver, ${ }^{41}$ a key component of moral distress is that individuals are prevented from fulfilling their perceived obligations. Nurses who experience moral distress often feel that they cannot make a significant contribution to decisions that they consider to be correct. There is a "gap" between nurses having empirical knowledge and their ineffective application of that knowledge, which can be addressed by empowering nurses. The strength of a person's perceived empowerment determines how one views obstacles and how much one overcomes the obstacles. Empowerment is considered to be a boost to one's sense of self-efficacy. Therefore, the more the nurses are empowered, the less frequently they experience moral distress. ${ }^{42}$

Another strategy to mitigate moral distress is to provide an institutional ethics consultation service. ${ }^{43}$ When health care providers have ethical concerns, they need support to facilitate open discussion. ${ }^{44} \mathrm{~A}$ unitbased approach offers a chance for multiple disciplines engaged in the care of a particular patient to access the consultation. ${ }^{35}$ It is suggested that embedding a clinical ethicist in the interprofessional team can promote the dialog between medical professionals who must explore difficult choices. ${ }^{45}$ Morally distressing situations almost always involve an interdisciplinary issue, such as a lack of effective communication between team members, or uncertainty about which medical service team is responsible. The inclusion of nurses in interdisciplinary rounds can help strengthen collaboration and communication when ethical issues arise and may subsequently reduce triggers of moral distress. Thus, with an interdisciplinary approach, ethical issues can be better understood and directly addressed. ${ }^{43}$

\section{Ethical approval}

Ethical issues are not involved in this paper.

\section{Conflicts of Interest}

All contributing authors declare no conflicts of interest.

\section{References}

1. Jubb J, Bensing JM. The sweetest pill to swallow: how patient neurobiology can be harnessed to maximise placebo effects. Neurosci Biobehav Rev. 2013;37:2709-2720.

2. Asai A, Kadooka Y. Reexamination of the ethics of placebo use in clinical practice. Bioethics. 2013;27:186-193.
3. Price DD, Finniss DG, Benedetti F. A comprehensive review of the placebo effect: recent advances and current thought. Annu Rev Psychol. 2008;59:565-590.

4. Blease C. Deception as treatment: the case of depression. J Med Ethics. 2011;37:13-16.

5. Lim EH, Seet R. Attitudes of medical students to placebo therapy. Intern Med J. 2007;37:156-160. 
6. World Medical Association. WMA Declaration of Helsinki - Ethical Principles for Medical Research Involving Human Subjects; 2018. https://www. wma.net/policies-post/wma-declaration-of-helsinkiethical-principles-for-medical-research-involvinghuman-subjects/. Accessed June 15, 2019.

7. Eippert F, Bingel U, Schoell ED, et al. Activation of the opioidergic descending pain control system underlies placebo analgesia. Neuron. 2009;63:533-543.

8. Hróbjartsson A, Gøtzsche PC. Placebo interventions for all clinical conditions. Cochrane Database Syst Rev. 2010; 1: CD003974.

9. Schafer SM, Colloca L, Wager TD. Conditioned placebo analgesia persists when subjects know they are receiving a placebo. J Pain. 2015; $16: 412-420$.

10. Benedetti F. Placebo-induced improvements: how therapeutic rituals affect the patient's brain. J Acupunct Meridian Stud. 2012;5:97-103.

11. Chua SJ, Pitts M. The ethics of prescription of placebos to patients with major depressive disorder. Chin Med J. 2015;128:1555-1557.

12. Shaw DM. Prescribing placebos ethically: the appeal of negatively informed consent. $J$ Med Ethics. 2009;35:97-99.

13. Scott PA. Key Concepts and Issues in Nursing Ethics. Galway: Springer Nature; 2017.

14. Miller FG, Colloca L, Kaptchuk TJ. The placebo effect: illness and interpersonal healing. Perspect Biol Med. 2009;52:518-539.

15. Bensing JM, Verheul W. The silent healer: the role of communication in placebo effects. Patient Educ Couns. 2010;80:293-299.

16. Nursing and Midwifery Board of Ireland (NBMI). Code of Professional Conduct and Ethics for Registered Nurses and Registered Midwives; 2014. https://www.nmbi.ie/NMBI/media/NMBI/Code-ofProfessional-Conduct-and-Ethics-Dec-2014_1.pdf Accessed June 18, 2019.

17. Touwen D, Engberts D. Those famous red pillsdeliberations and hesitations. Ethics of placebo use in therapeutic and research settings. Eur Neuropsychopharmacol. 2012;22:775-781.

18. Beauchamp TL, Childress JF. Principles of Biomedical Ethics. 7th ed. USA: Oxford University Press; 2013.

19. Fässler M, Meissner K, Schneider A, Linde K. Frequency and circumstances of placebo use in clinical practice - a systematic review of empirical studies. BMC Med. 2010;8:1-10.

20. Barnhill A. Clinical use of placebos: still the physician's prerogative? Hastings Cent Rep. 2012;42:29-37.
21. Confucius. The Analects of Confucius. Auckland: The Floating Press; 2010.

22. Kaptchuk TJ, Friedlander E, Kelley JM, et al. Placebos without deception: a randomized controlled trial in irritable bowel syndrome. PloS ONE. 2010;5:e15591.

23. Dooley D, McCarthy J. Nursing Ethics: Irish Cases and Concerns. 2nd ed. Dublin: Gill \& Macmillan; 2012.

24. Schildmann J, Ritter P, Salloch S, UhI W, Vollmann J. 'One also needs a bit of trust in the doctor...': a qualitative interview study with pancreatic cancer patients about their perceptions and views on information and treatment decision-making. Ann Oncol. 2013;24:2444-2449.

25. American Medical Association. Use of Placebo in Clinical Practice. 2019. https://www.ama-assn.org/ delivering-care/ethics/use-placebo-clinical-practice. Accessed July 5, 2019.

26. Barlem ELD, Lunardi VL, Lunardi GL, Dalmolin GdL, Tomaschewski JG. The experience of moral distress in nursing: the nurses' perception. Revista da Escola de Enfermagem da USP. 2012;46:681-688.

27. Rawas $H$. Moral distress in critical care nurses: a qualitative study. Int J Stud Nurs. 2019;4:35.

28. De Veer AJ, Francke AL, Struijs A, Willems DL. Determinants of moral distress in daily nursing practice: a cross sectional correlational questionnaire survey. Int J Nurs Stud. 2013;50:100-108.

29. Jafari $M$, Hosseini $M$, Maddah SB, Khankeh $H$, Ebadi A. Factors behind moral distress among Iranian emergency medical services staff: a qualitative study into their experiences. Nurs Midwifery Stud. 2019;8:195-202.

30. Huffman DM, Rittenmeyer L. How professional nurses working in hospital environments experience moral distress: a systematic review. Crit Care Nurs Clin. 2012;24:91-100.

31. Voyer $B$. Changes in the relations and roles of doctors and nurses. $\mathrm{Br} J$ Healthcare Manage. 2013;19:16-21.

32. Peter E, Liaschenko J. Moral distress reexamined: a feminist interpretation of nurses' identities, relationships, and responsibilites. J Bioethic Inq. 2013;10:337-345.

33. Jafari $M$, Hosseini $M$, Maddah SB, Khankeh $H$, Ebadi A. Factors behind moral distress among Iranian emergency medical services staff: a qualitative study into their experiences. Nurs Midwifery Stud. 2019;8:195-202.

34. Shorideh FA, Ashktorab T, Yaghmaei F. Iranian intensive care unit nurses' moral distress: a content analysis. Nurs Ethics. 2012;19:464-478. 
35. Altaker KW, Howie-Esquivel J, Cataldo JK. Relationships among palliative care, ethical climate, empowerment, and moral distress in intensive care unit nurses. Am J Crit Care. 2018;27:295-302.

36. Ulrich CM. Nursing Ethics in Everyday Practice. Indianapolis: Sigma Theta Tau; 2012.

37. Johnstone MJ, Hutchinson A. 'Moral distress' time to abandon a flawed nursing construct? Nurs Ethics. 2015;22:5-14.

38. Mclntosh B, Sheppy B. Effects of stress on nursing integrity. Nurs Stand. 2013;27:35.

39. Laabs C. Perceptions of moral integrity: contradictions in need of explanation. Nurs Ethics. 2011;18: 431-440.

40. Catlin A, Volat D, Hadley MA, et al. Conscientious objection: a potential neonatal nursing response to care orders that cause suffering at the end of life? Study of a concept. Neonatal Network. 2008;27:101-108.
41. Wocial LD, Weaver MT. Development and psychometric testing of a new tool for detecting moral distress: the moral distress thermometer. J Adv Nurs. 2013;69:167-174.

42. Browning AM. CNE article: Moral distress and psychological empowerment in critical care nurses caring for adults at end of life. Am J Crit Care. 2013;22:143-151.

43. Hamric AB, Epstein EG. A health system-wide moral distress consultation service: development and evaluation. HEC Forum, Springer. 2017.

44. Garros D, Austin W, Carnevale FA. Moral distress in pediatric intensive care. JAMA Pediatrics. 2015;169:885-886.

45. Bruce CR, Peña A, Kusin BB, Allen NG, Smith ML, Majumder MA. An embedded model for ethics consultation: characteristics, outcomes, and challenges. AJOB Empir Bioeth. 2014;5:8-18. 